Quinto Sol, No 1, pp. 75-102

\title{
LA ESTRUCTURA DE PODER EN LAS TRIBUS AMIGAS DE LA PROVINCIA DE BUENOS AIRES (1830-1850) *
}

\section{Silvia RATTO**}

La frontera con el indígena en la provincia de Buenos Aires había alcanzado una relativa estabilidad hacia fines de la época colonial. Garantizado el límite oficial de ocupación de tierras en el curso del Río Salado desde mediados del siglo XVIII, la relación con los indígenas tendió a descansar principalmente en vínculos pacíficos a partir de $1790^{1}$. Esta situación se revertiría poco después de las guerras de independencia por distintos factores. La creciente demanda de productos pecuarios por parte del mercado ultramarino surnada la caída del Litoral como principal abastecedor debido a la devastación sufrida durante la guerra civil, llevó a que el gobierno provincial tuviera como uno de sus objetivos prioritarios fomentar la producción ganadera en la campaña lo que derivó en una política de avance de la frontera que, quitando tierras de pastoreo al indígena lo desplazó hacia el sur. Este hecho, sumado a la creciente competencia por la

\footnotetext{
* Este trabajo es la versión modificada de un capítulo de nuestra tesis de maestria, La política de fronteras en la provincia de Buenos Aires (1810-1852) realizada bajo la dirección del Dr. Jorge Gelman. Agradezco la atenta lectura y valiosas sugerencias de la Dra. Martha Bechis.

"* Becaria de Perfeccionamiento del CONICET en el Instituto de Historia Argentina y Americana "Dr. Emilio Ravignani" (UBA).

${ }^{1}$. Los trabajos de Leonardo León Solís (1982) y Martha Bechis (1984) fueron pioneros en considerar que los procesos indígenas en Chile y Pampa-Patagonia debían ser explicados dentro de una única unidad de análisis; así surgió el término de área pan-araucana como marco para el estudio de los diversos tipos de contactos tanto intertribales como con la sociedad blanca a ambos lados de la cordillera de los Andes. Partiendo de esta premisa, tanto el período de extrema conflictividad en la frontera bonarense como la relativa calma que la sucede tienen su explicación en acontecimientos producidos en ambos espacios fronterizos. Ver el trabajo de León Solís (1990, cap. 1).
} 
adquisición de ganado que los indígenas ubicarían en los mercados chilenos y de las provincias del Interior, produjo la ruptura del equilibrio existente hasta el momento y el inicio de un período de extrema conflictividad ${ }^{2}$.

Luego de años de avances y retrocesos en las negociaciones con los indígenas en donde abundaron negociaciones de paz frustradas, firma de tratados que serian rotos por ambas partes, fundación de fuertes y oleadas de malones en respuesta, la llegada al gobierno de la provincia de Juan Manuel de Rosas en 1829 significó la implementación de una política indígena que, recogiendo proyectos esbozados desde la época de la independencia, lograría una relativa estabilidad en la frontera. La misma consistía en conjugar las dos estrategias que, intermitentemente y sin mayores formulaciones se habían estado aplicando hasta el momento: el establecimiento de paces y la guerra frontal ${ }^{3}$. El gobierno propondría determinadas condiciones para establecer las paces; las parcialidades que las aceptaran serían protegidas y auxiliadas económicamente cumpliendo a cambio de ello con ciertas obligaciones. Pero las tribus que no acordaran con el gobierno $y$, por el contrario, mantuvieran una actitud agresiva serían objeto de persecución por parte del ejército provincial.

De ahí que la eficacia de Rosas no derivara tanto de la originalidad de su política sino, por un lado, en haber podido fundir en un solo esquema de relación ambas estrategias y por otro en haber establecido dentro del presupuesto provincial una partida específica para hacer frente a los gastos de racionamiento de las tribus que aceptaran las paces ${ }^{4}$.

2. Sobre la expansión ganadera y la ocupación de tierras en la provincia de Buenos Aires ver los trabajos de Halperín $(1963,1969)$. Con respecto al incremento de la demanda de ganado por parte del mercado chileno y su repercusión en el comercio indígena, Bengoa (1985:45-46) y León Solís (1987).

3. La necesidad de aplicar esta política dual había sido esbozada en varios proyectos que, para el arreglo de la frontera se formularon en la época. El representante más relevante de esta postura sería, sin dudas, el coronel Pedro Andrés García (Gelman 1997:21-22).

${ }^{4}$. Uno de los problemas fundamentales que había conspirado hasta el momento contra el éxito de las políticas indígenas que se apoyaban en privilegiar los contactos pacíficos a través de obsequios a los caciques principales derivaba de la falta de recursos para sostener dicha política. Para la época colonial, ver las Memorias de los Virreyes del Río de la Plata. Al asumir la gobernación en 1829, Rosas expresaba a su ministro de Hacienda Manuel García la necesidad de obtener los fondos necesarios para "atender los gastos del negocio pacíico" por lo que le sugería hiciera ver a los hacendados los logros obtenidos por la política indígena desde que se había implementado un sistema de auxilios a determinadas tribus (AGN,III,1.6.5). En Chile, la política de obsequios y regalos a las 
Este aspecto de la política indígena se conoció en la época con el nombre de Negocio pacífico de indios e incluyó dos modalidades de relación con las parcialidades que aceptaron pactar con el gobierno. Mientras unas tribus, a las que denominamos aliadas, permanecieron en sus asentamientos en las pampas, otras, las amigas, se asentaron dentro de la línea de frontera gozando de la protección, y vigilancia, de los puestos fronterizos. En ambos casos, las tribus percibían auxilios económicos a través de la entrega de raciones mensuales de ganado yeguarizo y "vicios" 5.

El objetivo de este trabajo es analizar los cambios que se produjeron en el interior de las tribus amigas situadas en la frontera como consecuencia del contacto tan estrecho con la sociedad blanca. La existencia de un sistema de raciones que era percibido por todas las tribus del sistema lleva a preguntarse sobre la influencia que tuvo la distribución de estos bienes en los grupos indígenas. El otro eje tiene que ver con la función que cumplieron procesos internos de las tribus como, por ejemplo, la incorporación de grupos étnicamente diferentes, los matrimonios intertribales y la aplicación de la justicia "blanca", aspectos que nos permitirán indagar acerca del poder del cacique dentro de la tribu. Finalmente, un último aspecto que debe entrar en el análisis de esta problemática se encuentra en la situación de frontera que enmarca el proceso. En este sentido es un lugar común considerar a la frontera como "válvula de escape" para los sujetos marginados de la sociedad blanca. Planteamos que, de manera comparable, no debe desconocerse la función que la frontera debe haber cumplido para los integrantes de las tribus amigas.

\section{El sistema de raciones: ¿un camino hacia la redistribución?}

Una de las cuestiones que ha desatado fuertes polémicas dentro de la Antropología Política se refiere a las vías por las cuales se produce la diferenciación interna dentro de una sociedad igualitaria o tribal dando paso a una sociedad de jefatura. En estas discusiones la posición que gozó de mayor popularidad y reunió mas adeptos fue la que ponía el énfasis en la

principales jerarquías indígenas se canalizaba a través de los Parlamentos con las autoridades centrales. Para un análisis sobre el financiamiento de estos encuentros ver el trabajo de Mendez Beltrán (1982).

5. Para un análisis sobre la diferenciación entre tribus amigas y aliadas y los mecanismos de provisión de raciones ver Ratto (1994 a y b) 
función redistributiva del cacique planteando que, al convertirse en centro de captación y posterior distribución de bienes, la autoridad indígena adquiría un creciente poder sobre su gente. Esta también ha sido la posición dominante en la historigrafía argentina al hacer referencia a los resultados de la política indígena de Rosas. Según esta posición, si bien la misma produjo una relativa paz en la campaña bonaerense, la entrega de raciones a las tribus permitió el crecimiento de la hegemonía de algunos caciques; y permitió el surgimiento de poderosas confederaciones tribales de manera que, al caer el sistema rosista, la provincia se encontró ante una formidable fuerza hostil (Jones 1994:104)

Los autores que se refieren al incremento del poder de algunos caciques tienen en mente el caso del cacique Calfucurá con su intento de crear una Confederación indígena (Halperin 1963:57 y 1985:318-319). Pero un aspecto clave para el problema que nos planteamos es que el negocio pacífico, como ya se ha señalado, incluía dos mecánicas diferentes de relación con los indígenas. Mientras algunos grupos realizaban pactos de no agresión con el gobierno manteniendo su asentamiento fuera de la frontera (tal el caso de Calfucurá), otras parcialidades, por motivos diferentes, se avenían a situarse sobre la línea de frontera a inmediaciones de algún fuerte donde encontraban seguridad a la vez que eran controladas y prestaban servicios militares cuando eran requeridos. Teniendo en cuenta esta diferenciación sostenemos que las raciones no tuvieron la misma repercusión en el interior de los dos tipos de grupos. Y en este punto es necesario distinguir también entre el aumento del poder estructural del jefe dentro de su sociedad y el incremento del poderío indígena entendido como la capacidad del grupo de cometer actos de agresión contra otros. Una cosa no conlleva necesariamente a la otra.

Así, en las parcialidades que permanecieron en las pampas, la distribución de los bienes era realizada por el cacique y a la vez que permitió un incremento del poder del cacique pudo ser utilizada por éste para conformar o reforzar vínculos intertribales. No ocurrió lo mismo con las tribus asentadas en la frontera donde el Estado provincial aplicaba su control sobre determinadas áreas sociales siendo una de ellas, precisamente, la distribución de raciones. En estos casos sostenemos que el sistema de raciones pudo haber favorecido un incremento del poderío del grupo pero no así de la jefatura tribal. 


\section{Sobre la redistribución}

El origen de la jefaturas es un tema que ha producido un gran debate en el campo de la antropología política. La explicación de Service sobre el papel redistributivo del jefe constituyó la opinión que logró mayores adherentes y ocupó un lugar de significación por mucho tiempo. Para Service, el paso de una sociedad "igualitaria" a una jerarquizada, suponía esencialmente la sustitución de una economía dominada por la reciprocidad por otra que tenía a la redistribución como eje principal.

Ante esta propuesta que sitúa a la redistribución como motor de la estratificación social, se levantaron otras voces planteando que se estaban confundiendo los rasgos funcionales de las jefaturas con el origen en si de las mismas. Entre los principales detractores de esa postura se encuentra Robert Carneiro. El punto fundamental de su crítica se dirige a señalar que "lo que realmente obtiene un jefe de la distribución es estima, no poder. Sólo acumula poder cuando deja de distribuir extensamente comida y bienes y comienza a acumularlos" (Cameiro, 1981).

El problema se plantea, entonces, en términos de si la existencia de una figura redistribuidora dentro de un grupo alcanza para suponer que dicha persona ejerce un poder coactivo sobre su grupo. Para Morton Fried esto no sería así ya que la persona de más importancia de una red redistributiva "es tanto la víctima de su rol como su manipulador. Su función especial es reunir, no expropiar, distribuir, no consumir. En un conflicto entre la acumulación personal y las demandas de distribución es el primero que sufre. Cualquier otra cosa motiva acusaciones de acumulación y egoísmo y socava el prestigio del status central". (Fried 1985:138).

Eso lleva a tener un particular cuidado sobre el sentido que se da al término dado que existen distintos grados de redistribución. Es así que Marvin Harris habla de dos modalidades de redistribución: una igualitaria y otra estrabificada. En el caso de la primera el distribuidor trabaja mucho para producir lo que va a distribuir, guarda para si lo mínimo y una vez acabado el acto distributivo tiene menos de lo que tenía al principio. En la modalidad estratificada el distribuidor se abstiene de producir, se queda con la mayor parte y termina con más posesiones materiales que nadie (Harris 1986:242).

Una postura similar puede encontrarse en Oberg cuando analiza los mecanismos de diferenciación social en distintos tipos de organizaciones sociales. Según el autor los sistemas de 
incorporación de riqueza extema procedente de la sociedad blanca (a través de los malones o de las raciones gubernamentales) puede producir estratificación social tanto en tribus homogéneas como segmentadas, pero este hecho por si solo no altera la base económica de la tribu (Oberg 1973:196).

En resumen, la existencia de un jefe indígena que distribuye bienes excedentes en su comunidad no implica por si misma la existencia de una sociedad jerarquizada. Sólo en la medida en que esta distribución se realice en forma desequilibrada privilegiando unos grupos sobre otros puede plantearse la existencia de un poder centralizado. El sentido que se da al término redistribución en el trabajo está relacionado con to dicho anteriormente. No se trata de la concentración del excedente producido por la comunidad en un centro desde el cual los bienes vuelven a la misma. Lo utilizamos aquí en el sentido dado por Oberg de ingreso de excedentes de la economía blanca. En este caso puntual cabría agregar la percepción que tienen los indios amigos sobre la función de estos bienes. Así, las raciones son vistas por la comunidad como el pago por su ayuda y subordinación y en ese sentido es esperable que reviertan a toda la comunidad. Este es el sentido de la respuesta que dan los indios boroganos cuanto al pedir un pase para comerciar en la frontera son advertidos por la autoridad correspondiente que no hicieran daño en los establecimientos y que "mirasen con lastima al padre Rosas que hacía tantos esfuerzos por ello". Los boroganos contestaron que si Rosas "hacía esos sacrificios era porque ellos lo ayudan en la guerra" (Archivo General de la Nación, en adelante AGN, Sala X, legajo 24.9.1)

\section{El sistema de raciones}

En otro trabajo analizamos las condiciones en que las tribus amigas entraban en el negocio pacífico. Penuria económica, conflictos intertribales y desequilibrios en la población eran factores comunes en estas tribus amigas y que precisamente habrían llevado a estos grupos a interesarse por ingresar al negocio pacífico (Ratto 1997). La percepción de raciones y la defensa de sus enemigos era una oferta muy tentadora para la situación que estaban viviendo. Sería factible plantear que, precisamente al presentarse el acuerdo con el gobierno como una solución a los problemas mas acuciantes de la parcialidad, el cacique de la misma haya aumentado la estima dentro del grupo. En efecto, el acuerdo logrado por el cacique, al implicar la posibilidad de un mejoramiento económico por parte del grupo habría llevado a un fortalecimiento de su autoridad. ¿Cómo incidió sobre este panorama el sistema de raciones?. 
El ganado entregado por el gobiemo fue el articulo más importante para la recuperación económica y subsistencia de las tribus. Siendo su entrega regular, es de imaginar que en su distribución interna se reflejaría más nítidamente el posible papel redistributivo del cacique. Comenzando por el inicio de la cadena, resulta fundamental conocer los medios por los que se establecía el número de animales para cada grupo. En la década de 1870 Alvaro Barros denunciaba los abusos cometidos en la proveeduría de bienes a los indios amigos y relataba que cada indio recibía según su categoría y número de familia, ajuste que realizaba el comandante del fuerte "con acuerdo de su cacique". De manera que en este caso la autoridad tribal tenía en sus manos la posibilidad de discriminar creando o incentivando jerarquías internas (Barros 1972:141).

Durante el período rosista la situación fue totalmente diferente ya que la entrega regular de animales no guardaba una relación tan estrecha con la jerarquía de los indios en la tribu sino que, las cantidades entregadas guardaban estrecha relación con el número de indios existentes en cada toldería. Para ello, Rosas requería de los comandantes de los fuertes el envío de una nomina con la cantidad de indígenas a racionar realizándose el cálculo de una res diaria por cada 150 personas.

De ahí que, ante el incremento de la población, el gobernador decidiera unilateralmente aumentar el número de cabezas yeguarizas a entregar. Así, en enero de 1833 en vista de un padrón de la toldería de Venancio, Rosas informaba al cacique que había decidido aumentar las raciones mensuales (AGN,X,24.8.2). De manera similar, cuando la población de alguna toldería disminuía momentáneamente por algún movimiento de partidas, el comandante del Fuerte reducía el número de yeguas de ración en función de la menor cantidad de indios a mantener ${ }^{6}$. De todas maneras la proporción de ganado/hombre podía modificarse en función de la "buena comportación" de los indios. Así, en septiembre de 1836 se establecía que los indios boroganos de Fuerte Mayo recibirían una res diaria por cada 50 y 70 bocas (AGN, X,25.3.2).

Aún cuando en la determinación de las cantidades no le competía al cacique establecer los montos, recibidas las yeguas en las tolderías quedaba la posibilidad de que actuara como

\footnotetext{
${ }^{6}$ En varias oportunidades el comandante del fuerte Mayo restaba los animales que consideraba necesario cuando algunas partidas de boroganos abandonaban las tolderias para realizar sus operaciones de intercambio en otros puntos de la frontera.
} 
distribuidor de las mismas. Pero aquí nuevamente la intervención de las autoridades provinciales se sobrepuso a la autoridad cacical. E hecho de que ésta discriminara en la distribución interna de los bienes con la consiguiente posibilidad de que se creara un grupo de descontentos en la tribu era un peligro que Rosas no estaba dispuesto a correr. De ahí que aún el reparto de raciones dentro de las tribus fuera considerada una tarea que debía contar con la fiscalización de los comandantes de frontera.

En casi todos los casos analizados existió la tendencia de acaparamiento de bienes por parte de los caciques y la reacción del gobierno por corregir lo que se consideraba "un desorden". A poco de asentarse la tribu de Llanquelen en Federación, Rosas había reconocido la atribución del cacique en determinar quiénes debían percibir raciones dentro de su tribu. Al ponerse en funcionamiento el sistema de entrega de ganado el gobernador le ordenó al comandante del fuerte, José María Cortinas, que entregara a la tribu 400 yeguas pero que al hacer la entrega:

"es necesario grande abilidad por que si no la hay resultara que unos pocos se las apropien y los demas queden sin nada. Por esta razon es preciso que V.S. hable con el mismo cacique $y$ que acuerde con él el modo de hacer el reparto. Es decir a quienes se les debe dar y que numero" (AGN,X,24.5.2).

Sin embargo, poco tiempo despúes, y ante la posibilidad de que el acaparamiento de las raciones produjera disturbios en la tribu se revirtió la medida. En enero de 1835, el comandante del fuerte denunciaba que en la tribu las yeguas de ración "se las quedan los cabezas de toldos sin repartirlas" por lo cual se dudaba del reparto que se haya hecho de 30 bueyes y 15 arados que se enviaron por pedido del cacique para varios capitanes que querían sembrar. Ante la situación Rosas envió un parlamento con chasques de Catriel y Cachul para "contarlos y arreglarlos para que todos por igual participen de las yeguas de racion y que no se las agarren entre unos pocos" ( $A G N, X, 43.1 .3$ )

En la tribu borogana, durante el período de su asentamiento en Guamini, fuera de la frontera, también se reflejaba una tendencia de los caciques a la discriminación. En ocasión de la entrega de obsequios por la devolución de cautivos, Manuel Delgado, enviado del gobiemo para la tarea, denunciaba que:

"todo ese reparto se iso puramente a los borogas sin darle nada a los ranqueles, no se observo la orden que V.E. dio que los que abian dado cautivos y cautivas se les diese por que dijeron los caciques que ellos gobernaban en sus campos y que ellos 
tomarian las medidas que les pareciese" (Delgado a Rosas, 3 de mayo de 1834. $A G N, X, 24.9 .1)$

La respuesta de los caciques boroganos refleja daramente la diferencia existente entre estos grupos situados fuera del control estatal y aquellos que, ubicados en la frontera se encontraban permanentemente bajo la fiscalización de las autoridades fronterizas.

Nuevamente, en noviembre de 1833 Eugenio Bustos propuso a Rosas hacer él mismo el reparto de yeguas ya que "los caciques en lugar de repartirles a los que las necesitan se quedan ellos con la mayor parte y las restantes las reparten entre aquellos que son mas de su agrado quedando los que las necesitan sin ninguna parte para mantenerse". Sin embargo, la lejanía del grupo habría llevado a que el gobierno no se preocupara con empeño en modificar este esquema.

Producida la dispersión de la tribu en 1834, los grupos boroganos de Guayquil y Caneullan en Fuerte Mayo no parecen haber sufrido la injerencia de la autoridad militar en el reparto de bienes. Así lo expresaba el comandante del fuerte en mayo de 1836 que "jamas se ha mesclado en la distribucion [de raciones] que los casiques hacen a sus indios". Según las declaraciones del mismo la distribución que realizaban los caciques era absolutamente equitativa hasta el punto que:

"algunas veces suelen venir los cabezas a decir al jefe que abla que en la reparticion se han perjudicado por contentar a los indios y se han quedado con muy poca carne para el mes; [por 10 que] les he dado una yegua a cada uno y han salido contentos diciendole que tienen recursos de salir al campo a volear gansos, avestruces y tomar mulitas..." (AGN,X,25.3.2).

Si bien es posible suponer que los caciques hayan argumentado su pobreza con el objetivo de obtener más bienes, el reducido tamaño de estos grupos (unas 200 personas en total) daba escaso margen para el acaparamiento de las raciones.

Antes de su instalación en la zona de frontera, las tribus de Venancio, Catriel y Cachul vivían en la estancia Los Cerrillos, propiedad de Juan Manuel de Rosas localizada en el partido de San Miguel del Monte. Estos grupos recibían ganado yeguarizo y ovino para su subsistencia. Por las órdenes impartidas al capataz del establecimiento, Juan José Díaz, se desprende que 
habría existido algún tipo de acuerdo con los caciques con respecto a la forma de distribuir los animales. Sin embargo, y de manera similar a lo sucedido con Llanquelén, se producía la acumulación del ganado en manos de unos pocos por lo que se intentó también "ordenar" la distribución. En uno de los tantos repartos de ovejas, se recomendaba el capataz Juan Jose Díaz que convenía dar a cada toldo la parte que le corresponde "según el arreglo pues de otro modo solo disfrutan los que las reciben y los demás aun cuando pertenescan al cacique o capitan nada les toca" (AGN,X,23.9.4).

La actitud del cacique Venancio con respecto a las raciones no parece haber sido la de un "equitativo distribuidor". El capataz de Cerrillos, denunciaba que, cuando a fines de 1831 se requirió la ayuda de los indios amigos para perseguir a unos invasores chilenos, se entregó al cacique Venancio un rollo de tabaco y un saco de yerba "para que repartiese a su gente" pero denunciaba que "no lo ha hecho asi sino se queda el con las dos piezas" (AGN, X,24.5.2).

Producto del acaparamiento del ganado a expensas de sus indios o de obsequios particulares que recibió del gobiemo, lo cierto es que el cacique en 1831 ya poseía una invemada con "mucha lleguada y caballada" ubicada entre la cabeza del Toro, Blanca Vieja y arroyo del gualicho, custodiada por 30 chilenos armados de chuza (AGN,X,24.5.2). La percepción de estos recursos habrian solucionado "los grandes padecimientos" que Venancio sufría desde su llegada a las pampas ${ }^{7}$.

Dada la orden para que dichas tribus se asentaran sobre Tapalqué, Vicente González, comandante del Parque de Artillería de San Miguel del Monte, se ocupó de realizar los preparativos necesarios para el traslado de dichos toldos. En una comunicación a Rosas de febrero de 1832 expresaba que desde Tapalqué, los indios ya instalados le pedían constantemente vicios. González les previno que abandonaran esa práctica ya que las raciones serían en adelante suministradas en la misma guardia. Allí, confiaba que ante la fiscalización de las autoridades de campaña el reparto se ordenaría porque si bien era práctica habitual que los caciques:

"hasen unos repartos que lo mas suelen quedarse ellos con lo que se les manda para que repartan ... alli creo no le sera tan facil y por fin los indios que ven ya saben que se les ha mandado y a quien le han de hechar la culpa cuando les falte'

\footnotetext{
7. Sobre el ingreso e instalación del cacique Venancio en las pampas ver Villar y Jiménez (1995).
} 
$(A G N, X, 24.5 .3 A)$.

Hasta ahora los documentos mencionados reflejan un interés permanente del gobiemo por corregir la distribución poco equitativa que se practicaba dentro de las tribus y podría pensarse que la misma insistencia de las directivas implicaba la dificultad por lograr que las raciones llegaran a todos. Sin embargo, por lo menos en Tapalqué, hay datos concretos de haberse encontrado una solución a tal "desorden" habría llegado en 1836, cuando el comandante del cantón, Bernardo Echeverría, decidió realizar él mismo el reparto de las yeguas:

"A cada un indio de los que reciven les doy un papel firmado en el que van expresadas las yeguas que les corresponde cada 8 días poniendolas en numeros, letras y rayas para que ellos las cuenten".

Echeverría agregaba que para evitar resistencias por la implementación del nuevo sistema de reparto "e savido contentar a los caciques y en particular a Cachul que es el que mas trabajo suele dar en esta clase de arreglos" (AGN,X,25.3.2). La discriminación en la entrega de bienes a los caciques era una constante ${ }^{8}$. Sin embargo lo más llamativo es que la discriminación en la entrega de bienes no beneficiaba solamente a los caciques sino que era extensible a otras personas de la tribu y formaba parte de la estructura misma del negocio pacífico, como veremos más adelante. Así, el comandante de Tapalqué concluía su informe sobre el nuevo régimen de distribución de ganado notificando que "las yeguas que me sobraron de las 780, se las aumente a los que conocía debia aserlo" .

Los datos hasta aquí expuestos son suficientemente claros para verificar que el papel de redistribuidor del cacique se encontraba permanentemente interferido por la acción de las autoridades provinciales. Sin embargo el sistema de raciones no se limitaba a la entrega mensual de ganado yeguarizo sino que incluía el reparto de artículos de consumo y vestimenta en distintas coyunturas. La más regular era la entrega bimestral de estos bienes a las tribus asentadas en las cercanías de Tapalqué.

Los documentos que certificaban el envío de estos bienes incluían listados personales, es decir, relaciones que especificaban los artículos entregados a cada jeraquía de mando dentro la tribu (cacique, caciquillo, capitanejo) y listados que consignaban el envío de cantidades

${ }^{8}$. El cacique Venancio recibía 6 reses vacunas para su consumo personal. 
mayores de esos bienes para el resto de los indios. No se desprende de la documentación quién era el encargado de realizar estos repartos pero teniendo en cuenta que se trataba de Tapalqué en donde su comandante estaba particularmente interesado en evitar "desórdenes" podría suponerse que haya tenido también injerencia en esta tarea.

El análisis de los envíos personales refleja claramente la discriminación en cantidad y tipo de bien entregado en concordancia con las jerarquías internas ${ }^{9}$. Sin embargo, llama la atención, fundamentalmente en los artículos de vestimenta, que no existían patrones fijos sobre to que correspondía entregar a cada categoría indígena, tal bien y en tal cantidad para los caciques y así sucesivamente. Por el contrario, la diversidad que puede observarse sugiere que el enví no estaba solamente pautado por la posición del indio receptor en la estructura jerárquica de la tribu sino también por las necesidades particulares de cada uno de ellos.

Las raciones bimestrales no eran la única posibilidad que tenían los indios del común de acceder a bienes de la economía blanca. La formación de comitivas para actividades comerciales o parlamentarias era una ocasión posible para la percepción de bienes. En estos casos los artículos se entregaban a cada indio, china y muchacho esta vez sí, según cantidades rígidamente estipuladas. A las personas que encabezaban las comitivas, evidentemente indios de representación en la tribu, se le agregaban otros bienes, principalmente prendas de vestir, cuchillos, azadores, etc ${ }^{10}$. Pero también en estos momentos, además de los artículos de rigor, surgía la tendencia a conformar pedidos especiales o tal vez, pagar determinados servicios ${ }^{11}$.

La posibilidad de que los indios pudieran acceder a la percepción de bienes fuera de los

9. Los listados especificando la entrega de bienes de consumo y vestimenta a los indigenas se encuentran en los libros contables de la Tesorería de la Provincia de Buenos, AGN, Sala III.

${ }^{10}$. Los documentos que certifican la entrega de bienes a partidas indígenas en diferentes puntos de la campaña son numerosísimos y se hallan dispersos en distintos legajos. Ver por ejemplo, las entregas realizadas en Buenos Aires en enero de 1835 a distintos grupos (AGN,X,43.1.2); en la localidad de Monte en abril del mismo año (AGN,X, 25.1.1); en abril de 1839 desde la Chacarita de los Colegiales a los acompañantes del cacique borogano Caneullan (AGN, X,25.6.5).

11. En diciembre de 1835 Rosas ordenaba la entrega de 50 pares de espuelas "para compensar la entrega de cautivos" y 6 testeras de plumas punzó con 6 coletas de plumas "por una oferta que hizo a unos indios" (AGN, X,24.9.5). 
mecanismos tradicionales de producción y distribución interna de las tribus, sumado al hecho de la existencia de una política consciente de Rosas de diferenciar en la entrega no solamente con las autoridades tribales, refleja lo que a simple vista parecería una contradicción de la política indígena de Rosas. ¿ No sería razonable esperar que el gobierno intentara fortalecer las jefaturas para, por medio de la captación de la autoridad tribal, lograr el dominio de toda la parcialidad? La intromisión de las autoridades fronterizas en la distribución interna de las raciones y la posibilidad de que indios del común accedieran a bienes conspiraba contra esto. Sin embargo creemos que, precisamente la falta de textos escritos que estipularan a quiénes y cuánto dar era lo que permitía a Rosas la extrema flexibilidad con que se manejaba en estos asuntos ${ }^{12}$. Ni todos los caciques por igual ni todos los capitanejos recibian cantidades exactamente iguales. De ahí que existiera siempre la posibilidad de aumentar o disminuir las raciones en función del comportamiento de los caciques lo que a la vez servía de ejemplo para el resto de las tribus ${ }^{13}$.

Es llamativo no obstante, que el cacique Venancio recibiera mensualmente 1.000 pesos en billetes de a 20 y de a 10 pesos, entrega que debía realizar el comandante del fuerte de Bahía Blanca "a solas para que no lo sepan los demás indios" (Orden de Rosas a Martiniano Rodriguez, enero de 1835. AGN, X,25.1.4A). Probablemente esto se vinculara por un lado, con el escaso ascendiente que tenía el cacique sobre sus indios por lo cual, una entrega de este tipo podría haber causado profundo desagrado entre éstos. Por otro lado, el ocultamiento de este obsequio a Venancio tenía que ver con el intento de Rosas de crear una jerarquización de los caciques dentro del negocio pacífico. En esta pirámide cacical, los pampas Cachul y Catriel eran los principales ${ }^{14}$. Ellos recibian las mejores raciones y obsequios y además actuaban como

${ }^{12}$. Rosas justificaba la inexistencia de tratados escritos con los indígenas en el hecho de que éstos no podían ser considerados de igual manera que las "naciones civilizadas" (Levaggi 1995:129). Sobre la concepción de Rosas relativa a la negación de la existencia de los indigenas como "sociedad", ver el trabajo de Bechis (1996).

13. Los capitanejos Guayquimil y Jena recibieron 40 caballos porque "se han conducido bien y por cuyos consejos han servido de conducta a Cañuiquir"(AGN, X, 25.1.1).

${ }^{14}$. En octubre de 1835 Rosas ordenaba al comandante de Tandil que "si alguna vez ocurre a ese punto el cacique mayor Catriel ya sea a pasar alguna larga temporada o ya sea de visita, le obsequie y atienda y facilite lo necesario segun corresponde a su clan y esto mismo encargo respecto del caciuque mayor Cachul pues estos dos caciques son los principales y a quienes considera siempre como tales S.E. $(A G N, X, 43.1 .2)$ 
intermediarios para tratar con otras parcialidades ${ }^{15}$. El resto de los caciques amigos, conscientes de esta diferenciación intentaban lograr un mejor posicionamiento dentro del sistema mediante un contacto más directo con los caciques pampas. En 1832 en ocasión de un viaje de Catriel a Tandil como comisionado del gobiemo para repartir unas familias indias tomadas prisioneras en un enfrentamiento, los caciques asentados en el fuerte expresaron su deseo de mudarse a Tapalqué "para estar al lado de Catriel". Por otra parte, se han podido detectar alianzas matrimoniales que vinculan a distintos grupos con los caciques de Tapalqué ${ }^{16}$. Así, el incremento de estos grupos fue verdaderamente notable a lo largo del período analizado. De los cerca de 2.900 indios que estimamos para 1836 en función del ganado entregado de ración, en 1854, según los datos del censo provincial de 1854 existían en la zona unos 6.000 indios reducidos.

De todas maneras la posición privilegiada de los caciques pampas y la concentración de fuerzas indígenas en Tapalqué no parece haber derivado en un aumento del poder de las jefaturas. En enero de 1840, ante el requerimiento del comandante del fuerte para que los indios pertenecientes a sus parcialidades entregaran un ganado robado, los caciques contestaron que: "asen ellos cuanto pueden que algunos ollen sus consejos pero que hay entre ellos ... algunos malos que con estos me entienda yo del modo que me paresca significandome de un modo indirecto lo opuesto que es a sus leyes o costumbres e/ valerse ellos mismos de la fuerza en estos casos..." (AGN,X, 25.8.3; subrayado nuestro).

En principio podría pensarse que la respuesta de los caciques buscaba justificar el robo de ganado alegando su escaso poder sobre la tribu. Sin embargo el hecho de permitirle al comandante del fuerte que se entienda "del modo que le parezca" con los ladrones desvirtúa la idea de un encubrimiento de éstos y mostraría el escaso ascendiente que éstos tendrían tanto

\footnotetext{
${ }^{15}$ En el parlamento realizado en enero de 1835 con Llanquelen, Catriel y Cachul debian enviar sus chasques "diciendo que todo lo que yo mando es exactamente cierto y que la voluntad mía es la de ellos" (AGN,X,43.1.3). Cuando comenzaron las tratativas de paz entre el gobierno y Calfucurá para ajustar las paces y luego del parlamente que se realizaría entre chilenos y ranqueles para decidir los pasos a seguir, el cacique chileno debía reunirse con Rosas "y si no es posible con Catriel encargado por S.E al mismo efecto" (AGN,X,26.1.3).

${ }^{16}$. En agosto de 1837 la esposa del cacique borogano Caneullan de fuerte Mayo pidió autorización para viajar a Tapalqué "a celebrar un casamiento" (AGN,X,25.5.1). En octubre de 1839 el cacique Coliquinca también borogano de fuerte Mayo solicitaba un hermano con dos mujeres y mocetones que se hallaban en la toldería del finado Cachul en Tapalqué (AGN, X, 25.7.1).
} 
para proteger como para castigar a los delincuentes.

\section{Alianzas intertribales}

Relacionado con lo anterior, la incorporación de contingentes de otras tribus, en ocasiones enemigas, fue una práctica frecuente entre los grupos amigos. La misma no era nueva sino que puede considerarse una reproducción de patrones de comportamientos existentes entre las parcialidades indígenas en el período. Lejos habían quedado las épocas en que las unidades sociales estaban basadas únicamente en lazos de consanguinidad. Los cambios territoriales y las alianzas militares llevaron al surgimiento de lazos de dependencia de índole económica o política.

Miguel Angel Palermo, analizando la sociedad indígena pampeana-patagónica del siglo XVIII plantea que las relaciones intertribales tenían su origen en aspectos económicos y fundamentalmente en las incursiones en busca de ganado. Esta actividad requería el arreo y traslado tanto de animales como de mercaderías por distintas áreas bajo el control de otras parcialidades. Para ello debía lograrse el permiso de los caciques para transitar por dichas zonas. Una de las estrategias llevadas a cabo habría sido el matrimonio interétnico. Vinculado con estas relaciones matrimoniales se producian frecuentemente pasajes o rotaciones de personas o grupos que abandonaban su tribu de origen para instalarse con otras. El caso mas extremo de estas alianzas sería la constitución de grupos étnicamente mixtos cuyo origen podría haber sido la unión temporaria con un objetivo económico especifico que, por determinadas circunstancias derivaba en una alianza estable (Palermo 1991:175-179).

El mismo esquema de reagrupamientos en función de objetivos económicos es planteado por Leonardo León Solís en su análisis de los conflictos intertribales desarrollados en la Araucanía entre 1760 y 1780 . Este esquema avanza un poco mas allá que el planteo de Palermo al introducir dentro de las motivaciones, además de las de carácter económico, la lucha por el poder que se produjo en el interior de las tribus entre caciques gobernadores, lonkos, ulmenes y capitanes-conas. En ese contexto las alianzas con otros grupos respondían a la búsqueda de clientelas que permitieran el fortalecimiento político de los líderes. Estas alianzas basadas en las aspiraciones de los lonkos por captar el poder implicaba el riesgo de que las estrategias se inspiraran mas en las motivaciones personales de los sujetos que detentaban el poder que en el interés tribal global (León Solis 1994). 
A qué objetivos respondían las alianzas intertribales entre las tribus aliadas situadas fuera de la frontera?. La evolución de la tribu borogana en la década de 1830 es un claro ejemplo del intento por crear un liderazgo fuerte aún en contra del bienestar general de la parcialidad. Asentada a inmediaciones de Guaminí a partir de inicios de la década de 1830, la relación de la tribu borogana con el gobierno bonaerense fue una historia constante de alianzas y traiciones. Si bien participaba del negocio pacífico que formaimente implicaba la defensa de la provincia de ataques exteriores, mantenían una autonomía tal que les permitía sostener su relación con los ranqueles, tribu fuertemente hostil al gobierno bonaerense, ocultando y hasta participando en incursiones sobre la frontera. La organización política de la tribu a su ingreso a las pampas consistía en la pluralidad de la jefatura existiendo 6 caciques mayores que representaban a la parcialidad. Con el tiempo y vinculado a la necesidad de centralizar en una sola persona las relaciones con el gobierno, el cacique Cañuiquir comenzó a perfilarse como el jefe principal (Bechis 1994).

Al finalizar la expedición al sur de 1833 y ante el escaso éxito de la división que debía actuar sobre los ranqueles, Rosas presionó a los boroganos para que incursionaran sobre aquellos y rescataran los cautivos existentes en las tolderías. Mientras el cacique principal Cañuiquir hacía pocos esfuerzos por conseguir la devolución de los cautivos privilegiando el mantenimiento de las relaciones con los ranqueles, sus pares Rondeau y Melin deseosos de lograr un mejor posicionamiento en el contacto con Rosas, no dudaron en utilizar la fuerza para hacer cumplir su orden. Como resultado de esas incursiones algunos grupos ranqueles depusieron su actitud incorporándose a la tribu borogana en condiciones de subordinación ${ }^{17}$.

Pero paralelamente y ante el temor de que Rosas cambiara su recelo hacia la tribu en un ataque directo a ella, los boroganos decidieron pedir el auxilio de indígenas chilenos con la promesa de obtener ganado en la frontera. Al conocerse estos contactos Rosas convocó un parlamento al cual, ignorando la investidura de Cañuiquir para las negociaciones de paz, invitó al cacique Rondeau que se presentaba como más adepto que el primero. La presentación de Rondeau al bajar a parlamentar con Rosas evidenciaba la resistencia que encontró en la tribu para ejercer el papel de intermediario: "Yo vengo señor no a quitarle el derecho y la facultad que le tenemos dado a nuestro antiguo mayor Cañuiquir que el esta lleno de facultades para trabajar las paces hasta conduirla; perdone V.E. nuestras tropezas en nuestras leyes no se puede privar

${ }^{17}$. Para un análisis más detallado de este proceso ver Ratto (1996). 
a un hombre superior en las facultades que se le han conferido. Ayudarle si se puede en todo lo posible. Pero no quitarle el empleo. Estas son leyes de nuestros antiguos y estamos muy firmes de conservarlas y no abolirlas" .

En el parlamento Rosas recriminó duramente el llamado hecho a los chilenos haciendo responsables a los boroganos de cualquier ataque que pudiera sufrir la frontera. Esta advertencia habría llevado a Rondeau a retroceder en su invitación a los chilenos de incursionar sobre la provincia. Sin embargo el arribo de éstos ya se había producido y a mediados de 1834 se incorporaron a la tribu unos 500 indios chilenos bajo las ordenes de Calfucurá.

¿Cuál era entonces la situación de la tribu? Partimos de la base de que se trataba de una parcialidad con una jefatura múltiple donde no existía un poder que emanara del cargo 0 posición sino que la autoridad de los jefes debía ser permanentemente sostenida por sus habilidades ${ }^{18}$. E escribiente de los boroganos, Pablo Millalicán expresaba claramente la situación cuando describía a los boroganos como " infelices que se manejan con torpezas y se obedecen a ruegos y no con imperios" (AGN, X, 24.8.6).

El ascendiente obtenido por el cacique Rondeau en función de su papel de interlocutor con Rosas lo llevó a intentar incrementar su poder sobre la tribu. En febrero de 1834 ante el rumor de que los ranqueles habrían convencido a algunos boroganos para unirse en un malon, Rondeau hizo una junta con sus capitanes diciéndoles:

"vayan ustedes a robar o dar malon supuesto que son ustedes señores gobemantes de la tierra. Pero no les pese algun dia que yo tambien soy señor y yo sabre lo que he de hacer con ustedes" (en carta de Millalicán a Delgado, 7 de febrero de 1834, $A G N, X, 24.9 .1)$.

Estos intentos por el fortalecimiento de la jefatura también se observaban en el cacique Melin quien no dudó en utilizar la fuerza para hacer cumplir la orden de Rosas tendiente al rescate de cautivos en poder de los ranqueles incorporados a la tribu. El grueso de la tribu borogana, más cercana a los ranqueles con quienes habían creado fuertes vínculos de parentesco, se habría resistido al creciente poder de estos caciques $y$, contando

${ }^{18}$ Sobre la aplicación de los términos autoridad y poder en las sociedad indígenas pampeanas ver el excelente trabajo de Bechis (1989). 
circunstancialmente con el apoyo de grupos ranqueles, víctimas en distintas oportunidades de acometidas boroganas y un número importante de indios chilenos que habían visto cortadas sus intenciones de atacar los establecimientos fronterizos protagonizaron el ataque de Masallé donde fueron asesinados los caciques Rondeau y Melin.

¿ Fue distinta la situación en los grupos asentados en la frontera en donde el pacto con el gobierno implicaba, teóricamente, el abandono de su vinculación con otras etnias privilegiando la relacion con el blanco? En estas tribus la incorporación de personas se debían en varios casos a la toma de prisioneros en los enfrentamientos militares en los que los indios amigos participaban como milicias auxiliares ${ }^{19}$. En este caso una de las funciones de estos agregados era la toma de "dependientes" por parte de las jerarquías de la tribu ${ }^{20}$.

Otro objetivo se vinculaba a los intentos por equilibrar el desbalanceo en la relación entre hombres y mujeres (Oberg 1955:473). Así, por ejemplo, luego del ataque de Masallé dos grupos boroganos que respondían a los caciques Caneullan y Guayquil buscaron amparo en las cercanías del fuerte Mayo. En estos toldos, extremadamente reducidos, se reiteraba el esquema de un población masculina que excedía en gran medida a las mujeres posiblemente por el ataque sufrido en sus tolderías donde se habría producido el cautiverio de mujeres. La participación de un contingente de dichas tribus en una campaña contra los ranqueles llevada a cabo por el ejército provincial posibilitó que se incorporaran 39 personas de las cuales 13 eran mujeres y 22 muchachos $(A G N, X, 25 \cdot 1.4 A)$.

Pero más frecuente era la incorporación de grupos numerosos que en ocasiones

\footnotetext{
${ }^{19}$.Por ejemplo, en noviembre de 1832, las familias capturadas pertenecientes a las tolderías del cacique Guanquen fueron entregadas a Catriel a su pedido quien expresaba que junto con Cachul estaban viendo el modo de acomodar a las familias desgraciadas. de las 77 indias entregadas se repartieron: 4 a Tacuman, 14 a Calfiao, 7 a Chañabil, 3 a Calfiao chico, 6 a Cañuante, 3 a Guilitru, 4 a Peti, 8 a Antuan (todos caciques de Tandil), 5 a Venancio, 23 a Catriel para llevar a Tapalqué ( $A G N, X, 24.7 .3$ ) En junio de 1832, en una campaña contra los indios rebeldes comandada por el coronel Del Valle se obtuvieron 242 prisioneros indios. De éstos, Cachul se llevó 10 (AGN,X,24.7.1). En junio de 1835 en una avanzada a los ranqueles, se obtuvieron 25 cautivas y más de 80 prisioneros que fueron repartidos entre los caciques amigos que habian participado en la expedicion (AGN,X,25.1.4). En una campaña contra el cacique borogano Cañuiquir, los caciques amigos Venancio, Meliguer y Alon se repartieron los prisioneros obtenidos ( $A G N, X, 25.3 .2$ )

20. Sobre la función de los "dependientes" en el interior de las tribus ver Mandrini y Ortelli (1992)
} 
correspondían a grupos rivales. Para el sector que se incorporaba, la unión podría explicarse, como se ha visto, por la búsqueda de un mejor posicionamiento dentro del sistema vinculándose con los caciques más importantes. Para el grupo receptor se podría explicar en función de la inestabilidad misma de la alianza con el gobierno que podría llevar a que los grupos amigos buscaran incrementar sus fuerzas como una forma de presión y de nivelación de fuerzas con los contingentes blancos lo que llevaba a que, en ocasiones, se intentara ocultar el número real de los incorporados ${ }^{21}$. Por otro lado debe tenerse en cuenta que el haber optado por una vinculación tan dependiente del gobierno habría sido vista como una traición por otros grupos indígenas $\mathrm{y}$ en ocasiones los malones dirigidos hacia las estancias fronterizas eran particularmente cruentos cuando caían sobre tolderías indígenas. En ese contexto, la anexión de grupos suponía también un incremento de fuerzas para defenderse de esos ataques. Los riesgos sin embargo podían ser grandes en la medida que los grupos anexados pertenecieran a parcialidades rivales. El mayor de ellos involucraba la sublevación de los incorporados, situación que se produjo en distintas oportunidades.

El grupo que respondía al cacique chileno Venancio fue un ejemplo típico de rápido crecimiento de población merced a la incorporación de nuevos contingentes. En enero de 1832 Venancio notificaba que, con el agregado de indios chilenos que se le habian unido (desprendidos del grupo que a comienzos de 1831 había arribado a las pampas) su tribu alcanzaba a 200 indios de pelea ( $A G N, X, 24.5 .3 a)$. Un año más tarde en un recuento realizado durante un ejercicio en Azul el comandante consignaba la existencia de 440 hombres útiles de pelea (AGN,X,24.8.2). Poco tiempo después, producido el ataque de Masallé sobre la tribu borogana y producto de la dispersión de la parcialidad, un sector con aproximadamente 300 indios de pelea negoció su incorporación al grupo de amigos de Bahía Blanca inmediatos a Venancio. La relación entre los boroganos y la familia de Venancio era de extrema rivalidad y se remontaba a la época de la "guerra a Muerte" en Chile. La alianza gestada sobre esta base sería totalmente inestable y apenas dos años mas tarde su produjo una cruenta sublevación de los indios amigos inmediatos al fuerte y dirigida por los boroganos, en el cual fue asesinado el cacique Venancio (Ratto 1996:27-28).

${ }^{21}$ En 1834 el cacique Llanquelen anunciaba la incorporación a la tribu de su suegro Calquin con 70 personas más (AGN,X,24.5.4). Los censos realizados por el comandante de Federación para el ajuste de las raciones descubrieron que la anexión no solo había sido más numerosa que la que habia declarado el cacique sino que tambien estaba integrada por indios boroganos (AGN,X,43.1.3). 
Una situación similar se produjo entre las tribus de Catriel y Cachul asentadas en Tapalqué que incrementaron sensiblemente su población merced a la incorporación de nuevos grupos. A fines de 1832, no solo se había producido el traslado de parcialidades de Tandil (Tacuman) y Azul (Yanquelen y Añepan) (AGN, $X, 24.6 .4 A)$ sino también se incorporaron indios chilenos que pertenecían a la coalición que al año anterior había tenido en jaque a la frontera. El resultado también aquí fue la sublevación de grupos chilenos que se abatieron sobre las estancias fronterizas y principalmente sobre las tolderías pampas.

\section{La administración de justicia}

Sin intentar categorizar el tipo de organización social a que respondían las tribus amigas, buscamos aproximamos al conocimiento sobre la aplicación de justicia en estos grupos. Siguiendo a Service, en las sociedades segmentarias o tribales la resolución de los conflictos dentro de cada grupo recaía en las personas de mayor edad, en los ancianos o en los varones, es decir, las diferenciaciones de status de sexo y edad bastaban para solucionar conflictos dentro de cada unidad. En las sociedades de jefatura por encima del nivel familiar se encuentra la estructura de sociedad, pero no existen aún sanciones físicas coercitivas relacionadas con el monopolio de la fuerza practicada por el Estado. En estas sociedades la autoridad tiene la capacidad de intervención, sin embargo la misma no tiene carácter coercitivo sino que la jefatura emplea su buena influencia para conciliar las diferencias; la imagen más clara sería la de un árbitro que trata de convencer a las partes mediante sus facultades persuasorias (Service 1984:118-119).

En los grupos que estudiamos es posible afirmar que los caciques consideraran la aplicación de la justicia provincial como un medio de contar con un poder coercitivo que ellos personalmente no tenían. Dicha fuerza era suplantada por la que ejercían las autoridades de frontera, merced a un pedido expreso del cacique en una intervención que parecía buscar el fortalecimiento de las jerarquías de mando en la tribu. Veamos algunos ejemplos.

En las tolderías existentes en el fuerte Federación el cacique Llanquelén denunciaba que "unos pocos indios con un capitanejo no le guardan la obediencia debida al cumplimiento de sus disposiciones" y pedía en consecuencia que "si es de la aprovación de V.S. puede situar estos indios con sus familias a inmediacion de la Fortaleza a pie y con un hombre de su confianza a la 
cabeza para de este modo tenerlos a la vista y sugetos" ( $A G N, X, 24.8 .5$ ).

En otra oportunidad también entre este grupo indígena, se había producido una pelea en el toldo del capitanejo Yanquetruz producto de la cual el capitanejo, en compañía de su hermano Curupi asesinó al indio soldado Callubucal. El capitán Francisco Yanquelen intervino matando a Curupi y apresando a Yanquetruz a quien entregó al comandante del fuerte para que lo enviara a Rosas (Enero de 1846. AGN,X,17.7.2).

Sin embargo la utilización de estos mecanismos de control tenían sus riesgos cuando los comandantes de frontera intervenían en asuntos internos sin previo acuerdo con el cacique. En agosto de 1837 unos indios pertenecientes a la tribu del cacique Guayquil robaron la caballada del cacique. Apresados los culpables, el comandante del fuerte los interrogó sobre la existencia de otros indígenas que estuvieran pensando escapar a los enemigos a lo que respondieron que dos indios más tenía planeado huir tierra adentro. El comandante sin mediar consulta con el cacique los apresó y remitió "para que S.E. determine lo que alle por conveniente" $(A G N, X, 25.5 .1)$. En ocasión del reparto de raciones en Tapalqué en marzo de 1836 un indio pampa que acababa de recibir su ración pretendía cobrarla nuevamente. El comandante del fuerte envió una partida a alcanzarlo y una vez apresado, le dio "25 azotes delante de sus compañeros que a la sazón venían llegando a recibir la ración..." (AGN,X,25.3.2)

Más manifiesta era la apelación de los indígenas a distintas autoridades provinciales como un medio de utilizar un recurso hasta el momento fuera de su alcance y que garantizaba el logro de sus reclamos. Coincidimos en este punto con el planteo de Brad Asher en su análisis del funcionamiento del sistema judicial americano en las tribus asentadas al oeste del territorio de Washington a fines del siglo XIX. Asher señala dos momentos claves en el proceso. A partir de 1834 se estableció que los crímenes intratribales se mantenían dentro de la jurisdicción tribal en tanto los conflictos interraciales debían ser resueltos en los tribunales estatales. En 1885 se eliminó drásticamente la competencia tribal previendo la injerencia de las cortes federales en determinados delitos ocurridos dentro de los límites del país indio (Asher 1996:191). Este segundo momento fue considerado por muchos historiadores como el reflejo de una política tendiente a someter a los indios a la órbita estatal. Asher considera, por el contrario, que la mayor intromisión de la jurisdicción blanca no se debió solamente a presiones de los pobladores americanos asentados a inmediaciones de las reservaciones para precaverse de la violencia intraindígena sino también a un cambio en la actitud de los mismos indios al percibir la ley americana 
como una herramienta potencial para resolver disputas o proteger derechos que, con los mecanismos tradicionales tribales no satisfacían al damnificado (Asher 1996:200-201).

Lo más frecuente en estos casos era el reclamo de indios pertenecientes a la parcialidad. E rescate de indios ya sea que se hallaran en poder de cristianos o aún de otra tribu conllevaba el pago de una "recompensa" a sus poseedores ${ }^{22}$. La mecánica de la compensación para la recuperación de prisioneros de guerra no era nueva dentro de la sociedad indígena, to que se modifica es que, apelando al gobierno para el logro de este objetivo era aquél el que se hacía cargo del pago del rescate ${ }^{23}$

La posibilidad de recurrir al gobierno para obtener una compensación económica que, en las prácticas tradicionales debían ser cumplidas dentro de las parcialidades también comenzó a ser utilizada por los caciques en la práctica del pago de la novia ${ }^{24}$. En este caso el gobierno

\footnotetext{
${ }^{22}$ Aun cuando Rosas en distintas oportunidades había alertado sobre la distribución de prisioneros indígenas porque éstos no debían ser considerados como esclavos, en los hechos, el pago de un rescate por su devolución los acercaba a esa figura. Más evidente se tornaba la situación con la "compra" de estos prisioneros. En diciembre de 1834 el juez de paz de Lobos informaba que una india pampa tomada prisionera durante la expedición al Colorado y en poder del teniente José Aguilar había escapado y refugiándose en la estancia de Don Gregorio Rodríguez dirigió una queja al juzgado de paz por los malos tratos recibidos por la mujer de Aguilar pidiendo ser vendida al tal Rodríguez. Ante el pedido, Rosas determinó que se hiciera lugar al pedido de compra pero teniendo en cuenta el comprador que si el Estado redama la china para entregarla a sus deudos o para cualquier otra cosa deberá devolverla a cuyo fin deberá mostrar la constancia judicial de su compra para que el estado le devuelva la suma invertida ( $A G N, X, 43.1 .2)$.
}

${ }^{23}$ Los precios ofrecidos o pedidos por la devolución de prisioneros indios eran de lo mas variados discriminándose si el poseedor era vecino, militar o aún si era cristiano o indio. Al solicitar el cacique borogano Alon la entrega de 42 indios de su tribu tomados prisioneros en un enfrentamiento y que existían en su mayoría en Bahía Blanca, Rosas autorizó la devolución de dichos cautivos teniendo en consideración que "para exigirseles [la devolución] será preciso regalarles algo" por lo que envió el dinero del rescate especificando que debía pagarse entre 50 y 300 pesos según el tenedor fuera indio o cristiano de tropa, oficial o vecino (AGN,X,25.5.3). En octubre de 1841 ante la solicitud del cacique Collinao de dos indias de su tribu existentes en poder del cura y de una vecina de Bahía Blanca, los poseedores solicitan una compensación de 1.000 pesos moneda corriente (AGN,X,26.1.3). En 1838 el cacique borogano Millaquelen solicitaba desde Tapalqué una cuñada y dos sobrinos que se hallan en poder de un soldado de la Escolta de S.E. Se resolvió intentar la compra de dicho indio "pero sin forzarlo" para lo cual se autorizaba el pago de hasta 600 pesos (AGN, $X, 25.5 .3$ )

${ }^{24}$. Es probable que la práctica se remontara a las condiciones de la negociación llevada a cabo por Rosas en 1827 como representante del gobierno bonaerense, una de las cuales garantizaba la entrega de presentes en ocasión del casamiento de las hijas de los caciques. Ver nuestra tesis, La 
tomaba el compromiso de entregar los bienes correspondientes. Asi, en julio de 1835 los caciques Cachul y Cañuiquir solicitaban la devolución de los bienes pagados en la entrega de mujeres en matrimonio al fallecer el esposo y regresar la china a su tribu. En ambos casos el gobernador ofreció hacerse cargo del pago de las prendas invertidas ${ }^{25}$. En resumen, la apelación a la justicia provincial, de igual manera que se ha plantado para la distribución de las raciones gubernamentales, no parece haber sido una vía por la cual las jefaturas intentaran fortalecer su autoridad sobre la tribus sino por el contrario, un instrumento para mejorar la posición personal.

\section{La frontera como válvula de escape}

Se ha hablado ya del trabajo indígena en los establecimientos rurales de la campaña. Sin embargo, la distancia entre un trabajo coercitivo, integrante de las obligaciones impuestas a estos grupos y la libre decisión del indígena de conchabarse es muy difícil de establecer. En este último caso hay que tener en cuenta que la frontera no funcionaba solamente como válvula de escape para la población blanca sino que también habría cumplido la misma función para los indígenas ${ }^{26}$.

¿Cuáles habrían sido los incentivos para que los indios abandonaran su tribu?. En ciertos casos la frontera brindaba protección. Así, en septiembre de 1837 el comandante de Tapalqué informaba que el temor que algunas familias tenian a su cacique Cachul habia llevado a que varias de ellas se alejaran del cantón internándose en la campaña (AGN,X,5.5.1). La posibilidad de "refugiarse" en la frontera fue utilizada por otros indígenas de Tapalqué. Ante la

política indígena..., cap 1.

25. El primer caso se refiere a una india casada con un primo hermano del cacique borogano Cañuiquir. Durante un enfrentamiento la india es tomada prisionera por las fuerzas provinciales en tanto su esposo resulta muerto. Durante su cautiverio en Buenos Aires la china es tomada por el cacique Reilef con quien vuelve a casarse. Enterado del hecho, el cacique Cañuiquir pidió que se le devolvieran las prendas con que pago el casamiento. El segundo caso relaciona a las tribus de Cachul y Rondeau; la hermana de un indio de Cachul se había casado con el cacique borogano Rondeau y a su muerte es reclamado por su pariente. Guayquil, hermano de Rondeau pidió en cornpensación las prendas que le costó a su hermano (Ambos documentos en AGN,X,25.1.4).

26. Leiva plantea esta situación para el caso chileno. La frontera sería una oportunidad para que el individuo cambiara de pautas de conducta según le convenga; en este caso, si un araucano quería evadir su propia justicia nada mejor que cambiar de mundo (Leiva 1984). 
epidemia de viruela que en 1837 atacó a varios asentamientos de la frontera, algunos grupos se internaron en la provincia buscando ponerse a salvo de la enfermedad. Ante la dispersión de los indígenas Rosas solicitó a Cachul y Catriel que los indios pertenecientes a su tribu "que andan desparramados por las estancias es necesario los hagan volver a Tapalqué ... como estaban antes para atender a lo que sea preciso porque no es bueno que anden dispersos". Poco después Cachul notificaba que "mando [chasques] en cumplimiento de dicha orden a Camaron, Ciago, Monte y Lobos que es donde hay muchas tolderías y que estos se niegan a la obediencia no queriendo benir" (AGN,X,25.5.1)

Otro factor de atracción era simplemente la posibilidad de insertarse en la economía blanca mediante el trabajo en las estancias con la consiguiente obtención de dinero para la compra de bienes. Dentro de esta vía se puede distinguir el trabajo estacional y la instalación permanente de grupos dentro de las estancias, to que haría referencia a cierta desmembración de la tribu. Como ejemplos del primer caso, tanto los indios del Fuerte Independencia como los de Tapalqué se conchababan en las estancias de las inmediaciones de los fuertes ${ }^{27}$. Los hacendados habrían intentado establecer medios para revertir esta estacionalidad del trabajo mediante el expediente de endeudar a los indígenas a través de la entrega adelantada de dinero para obligarlos a mantenerse en el establecimiento. Pero esta estrategia no produjo los efectos deseados ya que los indios abandonaban igualmente la estancia con la deuda pendiente ${ }^{28}$.

Hay casos en que se produjo la instalación de grupos en las estancias. La posibilidad de migrar en familia habría estimulado a algunos sectores a abandonar su tribu de la misma manera que las condiciones brindadas por los estancieros para asegurar esta instalación ${ }^{29}$ en

\footnotetext{
27 Las referencias sobre contratación de indios de Independencia (AGN,X,25.6.1) y de Tapalqué, a quienes el comandante del fuerte entregaba "el pasaporte para que puedan [los indios] pasar hasta las ... estancias a ocuparse de sus trabajos de campo" (AGN, X, 25.3.2).

${ }^{28}$ El comandante de Independencia elevaba a Rosas la queja de los hacendados de la zona porque los indios contratados "se ausentan de sus patrones mudando de domicilio y en ese caso quedan debiendo a los referidos patrones" (AGN,X,25.6.1).

29. En la frontera de Araucanía, en Chile, los hacendados también se hallaban aquejados por la escasez de mano de obra y debieron buscar medios para asegurar la permanencia de los peones indígenas mediante distintas vías. Por un lado, permitían que éstos mantuvieran su estilo de vida tribal hasta el punto que se les autorizaba la instalación de obrajes para la producción de ponchos. Por otro lado, llegaron a otorgar tierras reproduciendo en parte, el sistema de inquilinaje (León Solís 19891990:196-197).
} 
donde los grupos familiares mantenian una separación física del resto del personal de la estancia, lo que haría referencia al mantenimiento de sus costumbres de vida pudiendo también acceder a la posesión de animales y tierras ${ }^{30}$.

\section{Conclusiones}

El objetivo del trabajo fue acercarnos al conocimiento de las modificaciones que pudieron haberse producido en el interior de las tribus amigas asentadas en la frontera luego de años de tan cercana convivencia con la sociedad criolla y de relaciones políticas con el gobierno bonaerense. Muchos de los aspectos que se han analizado: sistema de raciones, alianzas intertribales, intervención de la justicia provincial tenderían a hacer pensar que el resultado final sería una concentración de poder en los caciques de estos grupos. Por el contrario, hemos visto que en la mayoría de los casos, estos elementos no jugaban libremente en el interior de las parcialidades sino que estaban intermediadas por la presencia del Estado y las autoridades provinciales. Ello no significa suponer que estos grupos eran víctimas pasivas del gobiemo ya que también hemos visto que precisamente la posibilidad de acceder a esas otras fuentes de poder era utilizada personalmente por distintos integrantes de la tribu para obtener ciertos beneficios.

En síntesis, el negocio pacífico de indios tendió a conformar una jerarquización dentro de las tribus integrantes del sistema en donde se privilegió permanentemente a los caciques pampas asentados en Tapalqué con los cuales la relación de amistad era muy fuerte. La contrapartida indígena fue, por una parte, la aceptación de esa jeraquización y la búsqueda de un mejor posicionamiento en este esquema $y$, por otra parte, la búsqueda de un mejor status de vida por parte de algunos integrantes de las tribus. Un caso ejemplar de esto último es el del cacique borogano Caneullan, cabeza de uno de los grupos que, luego de Masallé buscaría amparo en el Fuerte Mayo. A partir de 1836, alegando razones de seguridad, su residencia habitual sería la Chacarita de los Colegiales donde era hospedado y obsequiado convenientemente. Alí recibía

\footnotetext{
30. En un caso la familia de la china Juana Grande compuesta de 19 personas que fue trasladada de la estancia Las Víboras propiedad de Anchorena a otra perteneciente a Don Ildefonso Ramos Mejía. Para realizar la "mudanza" se otorgó a la familia un plazo de "ocho o doce dias mientras arreglan y acomodan sus trabajos" ( $A G N, X, 25.4 .4)$ y para que pudieran trasladar sus "toldos familia y animales de su pertenencia" (AGN,X,25.3.5). Otro caso corresponde al cacique Felipe, perteneciente a una de las tribus asentadas en Fuerte Mayo, que tenía una pulpería a inmediaciones de la estancia de Felipe Barrancos, en la guardia de Luján, donde vivía con su mujer Clara, sus hijos Ventura y Santiago, su hermano Santiago, su mujer Jacinta y los hijos de ese matrimonio ( $A G N, X, 16.8 .4$ ).
} 
partidas provenientes del asentamiento fronterizo al que se dirigía en muy escasas ocasiones.

Finalmente, si dirigimos nuestra mirada hacia el final del período que analizamos se puede comprobar que el "negocio pacífico" no produjo una concentración de poder en los caciques fronterizos y sí, por el contrario, la importancia relativa de los caciques tapalquinos. Cuando en 1852 cayó el régimen rosista, las únicas fuerzas indígenas que se levantaron inmediatamente contra Buenos Aires fueron las de Calfucurá. La actitud de los indios pampas que respondían a Catriel y Cachul comenzó con una serie de malones sobre los establecimientos fronterizos uniéndose pocos años después a la coalición encabezada por el cacique chileno. Significativamente el hecho que decidió su participación en la misma fue la interrupción en el envío de las raciones mensuales. Nada se dice del resto de los indios amigos lo que hace suponer su abandono de la frontera o su asmilación a la sociedad provincial. 


\section{Bibliografía}

ASHER, Brad (1996). "Their own domestic difficulties: intra-Indian crime and white law in western Washington territory, 1873-1889", en: The Western Historical Quarterly, Vol XXVII, Núm 2.

BARROS, Alvaro (1972). Fronteras y territorios federales de las pampas del sur. Buenos Aires, Hachette.

BECHIS, Martha (1989). "Los lideratos pampeanos en el área araucano-pampeana en el siglo XIX: autoridad o poder?", en: I Congreso de Etnohistoria argentina. Buenos Aires, Facultad de Filosofía y Letras.

BECHIS, Martha (1994). "Política indígena pampeana en una carta borogana de 1830". mimeo. BECHIS, Martha (1996). "Una acción de Juan Manuel de Rosas ante el gobierno de Martín Rodriguez por derecho de reivindicación de ganados", en Revista de Historia del Derecho "R. Levene", No. 32.

CARNEIRO, Roberto (1981). "The chiefdom: precursor of the state", en: Jones and Kautz (eds): The transition to the statehood in the New World. Cambridge, Cambridge University Press. FRIED, Morton (1960). "On the evolution of social stratification and the state", en: Diamond (comp) Culture in history. New York, Columbia University Press.

GELMAN, Jorge (1997). "Un funcionario en busca del Estado. Pedro Andrés García y la cuestión agraria bonaerense, 1810-1822". Mimeo.

HALPERIN DONGHI, Tulio (1963). "La expansión ganadera en la campaña de Buenos Aires", en: Desarrollo Económico, vol 3.

HALPERIN DONGHI, Tulio (1972). Argentina, de la independencia a la confederación rosista. Buenos Aires, Paidós.

HARRIS, Marvin (1986). Introducción a la Antropología general. Madrid, Alianza.

JONES, Kristine (1994). "Indian- Creole negotiations in the southern frontier", en" Szuchman and Brown (eds) Revolution and restoration: the rearrangement of power in Argentina, 1776-1860. Lincoln and London, University of Nebraska Press.

LEIVA, Arturo (1984). El primer avance a la Araucanía. Angol. Universidad de la Frontera, Temuco.

LEON SOLIS, Leonardo (1982). "La Corona española y las guerras intestinas entre los indigenas de Araucanía, Patagonia y las Pampas, 1760-1806", en Nueva Historia. Año 2 (5), Londres. LEON SOLIS, Leonardo (1990). Maloqueros y conchavadores en Araucanía y las pampas 1700-1800. Universidad de la Frontera, Temuco.

LEON SOUS, Leonardo (1993). "El parlamento de Tapihue, 1774", en: Nutram Año IX, No 32. 
Santiago.

LEON SOLIS, Leonardo (1994). "Guerra y lucha faccional en la Araucanía (1764-1777)", en: Proposiciones No. 24.

LEVAGGI, Abelardo (1995). "Tratados celebrados entre gobiemos argentinos e indios del sur de Buenos Aires, Santa Fe, Córdoba y Cuyo (1810-1852)", en Revista de historia del Derecho "R. Levene", 30. Buenos Aires.

MANDRINI, Raúl y ORTELLI Sara (1992). Volver al país de los araucanos. Buenos Aires, Sudamericana.

MENDEZ BELTRAN, Luz María (1982). "La organización de los parlamentos de indios en el siglo XVIII", en VILLALOBOS (ed.) Relaciones fronterizas en la Araucanía. Chile, Ediciones Universidad Católica de Chile.

OBERG, K (1955). "Types of social structure among the lowland tribes of South and Central America", en: American Anthropologist, 57 (3)

PALERMO, Miguel Angel (1991). "La compleja integración hispano-indígena del sur argentino y chileno durante el período colonial" en: América Indígena LI (1).

RATTO, Silvia (1994a). "Indios amigos e indios aliados. Orígenes del negocio pacífico en la provincia de Buenos Aires (1829-1832)", en Cuadernos del Instituto Ravignani No. 5.

RATTO, Silvia (1994b). "El sistema de racionamiento de las tribus amigas en la provincia de Buenos Aires (1832-1840)" Ponencia presentada en las XIV Jornadas de Historia Económica, Universidad Nacional de Córdoba.

RATTO, Silvia (1996). "Conflictos y armonías en la frontera bonaerense 1832-1840" en: Entrepasados No. 11. Buenos Aires.

RATTO, Silvia (1997). " Redistribución o enriquecimiento personal? Algunas consideraciones sobre el rol de los caciques de tribus amigas en la provincia de Buenos Aires", Ponencia presentada al Segundo Encuentro Argentino-Chileno de Historiadores. Santiago de Chile.

SERVICE, Elman (1984). Los origenes del Estado y la civilización. Madrid, Alianza.

VILLAR, D. y JIMENEZ J.F. (1995). "Don Venancio, Montero y los otros. Mapuches y blancos en el espacio fronterizo pampeano: estrategias de ingreso e instalación (1827-1836)", Ponencia presentada al Primer Encuentro Argentino-Chileno de Historiadores. Universidad Nacional de Cuyo, Mendoza. 